\title{
A novel volumetric analysis using cad/cam scanners in gingival recession treatment
}

Hacer Sahin Aydinyurt ${ }^{1 *}$, Abdullah Seckin Ertugrul ${ }^{2}$

\begin{abstract}
Objective: In this study, randomized clinical trial (RCT), the aim was to compare clinical periodontal data of subepithelial connective tissue graft (SCTG) group and SCGT+enamel matrix derivatives (EMD) group in terms of gained gingiva volume (GGV) and gained gingiva surface area (GGSA) by scanners of computeraided design/computer-aided manufacturing (CAD/CAM) devices.

Material and Methods: In this study, a total of 35 Miller class I-II gingival recession defects were involved ( $\mathrm{n}=17$ in SCTG group, $\mathrm{n}=18$ in SCTG+EMD group). In addition to, periodontal clinical parameters, and three dimensional (3D) images were recorded by using CAD/CAM system before the treatment, at the $1^{\text {st }}$ month and the $6^{\text {th }}$ months after the treatment. The images were superimposed by using softwares and GGV, and GGSA were calculated.

Results: There was no significant difference in terms of GGV and GGSA values at the $1^{\text {st }}$ month and $6^{\text {th }}$ months between SCTG+EMD and SCTG groups. Similarly, there was no significant difference in periodontal clinical parameters between groups.

Conclusion: Images obtained from CAD/CAM system can be easily used in calculating GGV and GGSA data after the gingival recession treatment and in determining of the success of administered treatment. It is expected that the evaluation of the success of many therapeutic approaches for periodontal treatment will be carried out by using CAD/CAM system in the future.

Keywords: Subepitelial connective tissue grafts, Enamel matrix derivatives, Gingival recession, CAD/CAM, Dentistry, Periodontics
\end{abstract}

\section{Introduction}

The clinical exposure of root surfaces due to apical migration of the gingival tissue margin to the cementenamel junction is named as gingival recession (GR). Various factors may underpin formation and progression of GR. Tooth position, incorrect tooth brushing techniques, and chemical or mechanical trauma are among these etiological factors. (1) Biological width which is composed by epithelial attachment and subjacent connective tissue is considered as an adaptation mechanism of the body occurring where epithelial tissue is perforated by teeth and GR may arise from its violation by various dental restorations. (2) GR causes cervical dentin hypersensitivity, pain, and difficulty while toothbrushing. (3) A large number of treatment methods have been developed for the purpose of covering the exposed root surfaces. Among these methods, subepithelial connective tissue graft (SCTG) is the most commonly used treatment modality with a high success rate. Many studies support SCGT, when administered with coronally positioned flap (CPF), as

an effective procedure for covering exposed root surfaces. Therefore, SCTG administered in conjunction with CPF is considered as the gold standard in the coverage of exposed root surfaces. (4)

Enamel matrix derivatives (EMD) are used in the treatment of GR in combination with different surgical techniques. EMD are believed to induce the regeneration of periodontal tissues by virtue of their main role in the development of cementum. Histological studies have shown that administration of EMD on to root surfaces provides the formation of new bone, new periodontal ligament, and acellular cementum. (5)

Many measurement methods are employed to evaluate the success of periodontal treatment. Most frequently used clinical measurement method is periodontal probing. By periodontal probing, clinical measurements such as GR, width of keratinized tissue, and the level of the gingival margin can be done with accuracy close to $0.5 \mathrm{~mm}$.(6). 
The success of periodontal treatment can also be determined by using reproducible photographs. Nevertheless, it is possible to receive only twodimensional data from photographs. (7). On the other hand, there are also methods where gingival volume can be calculated in three-dimensional space (3D) by the scanners of computer-aided design/computer-aided manufacturing (CAD/CAM) devices. $(8,9)$

CAD/CAM system was developed in order to collect $3 \mathrm{D}$ images from teeth and surrounding soft tissue. In order to record the 3D morphology of the teeth and supporting tissues, impressions are clinically taken from patients. Plaster models are prepared by using laser scanner or scanners of CAD/CAM system and thus 3D digital models are prepared.(9) It is also possible to take a direct intra-oral image through scanners of CAD/CAM system. Problems which may arise during examination by conventional techniques, transporting it to laboratory and plaster casting can cause inaccuracy in determining the size of the prepared model. (10). A preliminary study was carried out to determine whether the cemento-enamel junction was correctly identified with $\mathrm{CAD} / \mathrm{CAM}$ before the main study. The aim was to detect cemento-enamel junction and to compare the dimensions of GR (gingival recession height $(\mathrm{GRH})$ and gingival recession weight (GRW)) using probing and CAM/CAM. For this purpose 20 Miller class I-II GR were included in the preliminary study. GR defects were measured by probing and CAD/CAM device by the same researcher (Sahin Aydinyurt H.). As a result no significant difference was found in terms of GRH and GRW. This study showed that cemento-enamel junction was easily and correctly detected by CAD/CAM which was incompatible with clinical probing. In light of these information, we aimed to measure gained gingival volume $(\mathrm{GGV})$ and gained gingival surface area (GGSA) values of patients who have Miller class I and class II GR after periodontal treatment by using CAD/CAM system and to compare results of SCGT group and SCGT+EMD group.

\section{Material and Methods}

\section{Study populations}

In this study, we included a total of 35 GR defects in 35 patients, who applied to the clinic with complaints of poor aesthetic and/or root surface sensitivity. Follow-up of the patients were conducted throughout the study based on these criteria: individuals should have no systemic disease, should be non-smokers of cigarette or tobacco products, not in a pregnancy, have not used any antibiotics or medications with an impact on the immune system within last 6 months, have GR classified as Miller class I or class II, have GR depth of $\geqslant 2 \mathrm{~mm}$, have no decay or restoration on the vital teeth which will be operated, have no operation history with regard to GRs for related tooth area. The materials and methods of this study were approved by the Non-Drug Clinical Researches Ethics Committee

$\begin{array}{lll}\text { of } \quad \text { Yüzüncü } & \text { Y1l University } \\ \text { (B.30.2.YYU.0.01.00.00/32). } & & \end{array}$

\section{Study Groups:}

In SCTG group 17 of GRs defects and in SCTG+EMD group 18 GRs defects were treated. While GRs in SCTG group were treated by SCTG and CPF combination therapy, EMD (Emdogain, Straumann, Basel, Switzerland) was additionally used in GR treatments of SCTG+EMD group. Patients were randomized by complete randomization method (SPSS 15; SPSS Inc., Chicago, IL, USA) to assign them into groups.

\section{Pre-surgical Procedure:}

Patients were informed about the potential causes of GRs. Causative habits of GR have been eliminated. Baseline periodontal treatments of the patients were performed. Plaque index (PI) (11), gingival index (GI) (12), probing pocket depth (PPD) (mm), clinical attachment level (CAL) (mm) were recorded before periodontal treatment. We prepared patients with total PI scores less than \% 15 for the surgical procedure (O'Leary et al 1972). Pre-treatment 3D soft tissue images were taken by CEREC Omnicam (Sirona Dental Systems GmbH, Bensheim, Germany) from intra-oral region. Recipient zone was prepared using the Langer method. SCTG was extracted ipsilaterally with the operation site from the palatal region between distal of canine and mesial of 1 st molar tooth. Incision was performed in parallel with free gingival margin using Harris graft knife (Harris Double Blade Graft Knife, H \& H Company, Ontario, CA, USA). Harvested graft was implanted to recipient zone so that its periosteal side could face with root surface and overhangs defect borders by $1 \mathrm{~mm}$. In order to remove the smear layer on the root surface of the teeth in SCTG+EMD group, 24\% EDTA (Prefgel, Straumann, Basel, Switzerland) was applied for two minutes onto the root surface and operation site was washed with normal saline in order to remove any residual EDTA. EMD was applied to entire root surface compatible with manufacturer's instructions.

\section{Post-surgical Procedure}

We have collected 3D images and clinical parameter values from patients during follow-up examinations at the 1st and the 6th month after the periodontal surgery. 3D images of soft tissue were taken intraorally with CEREC Omnicam ${ }^{\circledR}$ device at the commencement of treatment as well as at the postoperative 1st and 6th months (Fig. 1-2). We recorded measurements in rst.img format which is a file extension of CEREC system ${ }^{\circledR}$. The operation site was cut out from the image which was recorded at the 1 st and at the 6th month. We also made a scanning taking the neighboring teeth as reference and saved repeated measurements of the operation sites. We filed baseline, 1st month and 6th month images of each patient separately and converted these files into the 
STL (standard tessellation language) format. We assessed the data which was converted into STL format using Mimics 10 (HQ Materialise, Leuven, Belgium), a 3D analysis software. Images of each patient which were taken in three different time points were overlapped on Mimics 10 software. GGV and GGS measurements were made on the overlapped images. We calculated the GGV and GGSA of the difference in tissue as obtained after overlapping the $3 \mathrm{D}$ images by the software. Changes at the 1 st and the 6 th month after treatment were calculated with respect to pre-treatment images (Fig. 1-2).

\section{Statistical Analysis:}

Statistical analysis was performed by using the SPSS 15 (SPSS Inc., Chicago, IL, USA) program. Kolmogorov-Smirnov normality test was performed on all available data. Nonparametric tests were applied since the data did not have a normal distribution. Friedman Test was employed for in-group analysis of clinical parameters. In the event of a significant ingroup variance, Wilcoxon Test was performed in order to determine which group caused such difference. Mann-Whitney U-Test was used in two group evaluation. Evaluation of GGV and GGSA data from 3D images was done by Wilcoxon Test. MannWhitney U Test was applied in inter-group evaluations. Confidence interval of $95 \%$ and significance level of 0.05 was based on in order to assess statistical significance of results.

\section{Results}

In this study, a total of 35 patients, comprising of 18 females and 17 males, were involved. Average age of the individuals was calculated as $42.4 \pm 7.70$. Evaluation of the age data revealed there wasn't statistical difference between two groups $(p>0.05)$. In terms of baseline values of clinical parameters, no significant difference was found between groups $(p>0.05)$. There was no significant difference in changes of PI, GI, CAL, and PD at the 1st and the 6th month between two groups $(p>0.05)$ (Table-1). We overlapped pre-treatment, and post-treatment 1 st and 6th month STL images and we calculated the gain in the GR region in volume $(\mathrm{mm} 3)$ and surface area $(\mathrm{mm} 2)$. In all measurements, the difference between pre-treatment and 1st month after treatment and the difference between pre-treatment and 6th month after treatment were recorded numerically. Likewise, the difference between 1 st and 6th month was recorded (Figure 1-2).

In SCTG+EMD group, average GGV value was $14.5 \pm 7.5 \mathrm{~mm} 3$ at the $1 \mathrm{st}$ month and $11.5 \pm 6.72 \mathrm{~mm} 3$ at the 6th month. In SCTG group, average GGV value was $11.2 \pm 6.36 \mathrm{~mm} 3$ at the 1st month and $8.6 \pm 5.0$ $\mathrm{mm} 3$ at the 6 th month. There was no significant difference in GGV value at the 1st month between SCTG+EMD and SCTG groups $(\mathrm{p}>0.05)$. Similarly, there was no significant difference in $\mathrm{GGV}$ value at the 6th month between SCTG+EMD and SCTG groups ( $\mathrm{p}>0.05)$ (Table-2).

The mean GGSA value was $49.37 \pm 18.28 \mathrm{~mm} 2$ in SCTG+EMD group, and $41.93 \pm 17.43 \mathrm{~mm} 2$ in SCTG group. In 6th month, the mean GGSA value was $42.75 \pm 16.82 \mathrm{~mm} 2$ in SCTG+EMD group and $33.13 \pm 14.36 \mathrm{~mm} 2$ in SCTG group. There was no significant difference in GGSA value at the 1st month between SCTG+EMD and SCTG groups $(p>0.05)$. Similarly, there was no significant difference in GGSA value at the 6th month between SCTG+EMD and SCTG groups $(\mathrm{p}>0.05)$.

According to Spearman Rho correlation analysis results, a statistically significant positive correlation between PI, GI, PD, and CAL scores and RW and RD scores was determined $(\mathrm{p}>0.05)$. But statistically insignificant negative correlation between PI, GI, PD, and $\mathrm{CAL}$ and $\mathrm{KGW}$ scores was determined $(\mathrm{p}<0.05)$. It has been observed that there was a statistically significant negative correlation between PI, GI, PD, and CAL scores and (GGSA and GGV scores $(p<0.05)$. Statistically significant negative correlation was determined between RD and RW scores and GGSA and GGV scores $(p<0.05)$. Statistically significant, positive strong correlation was determined between KGW and GGSA and GGV scores $(\mathrm{p}<0.05)$ (Table-3).

Table 1: Pre- and post-operative clinical parameters of the test and control groups ( $\mathrm{t} 0$ : Pre-operative, $\mathrm{t} 1: 1$ month after surgery, t6: 6 months after surgery) Statistically significant: $\mathrm{p}<0.05$. NS: Not significant.

\begin{tabular}{ccccc}
\hline & & Test Group SCTG+EMD & Control Group SCTG & $\begin{array}{c}\text { Between Test and Control Groups } \\
\text { (p) }\end{array}$ \\
& $\mathbf{t 0}$ & $0.91 \pm 0.21$ & $0.87 \pm 0.37$ & $\mathrm{NS}$ \\
& $\mathbf{t 1}$ & $0.75 \pm 0.49$ & $0.84 \pm 0.44$ & $\mathrm{NS}$ \\
& $\mathbf{t 6}$ & $0.78 \pm 0.48$ & $0.79 \pm 0.49$ & $\mathrm{NS}$ \\
\multirow{2}{*}{ GI } & $\mathbf{t 0}$ & $1.01 \pm 0.20$ & $0.92 \pm 0.47$ & $\mathrm{NS}$ \\
& $\mathbf{t 1}$ & $0.89 \pm 0.42$ & $0.82 \pm 0.48$ & $\mathrm{NS}$ \\
& $\mathbf{t 6}$ & $0.94 \pm 0.46$ & $0.81 \pm 0.61$ & $\mathrm{NS}$ \\
\multirow{2}{*}{$\mathbf{P D}$} & $\mathbf{t 0}$ & $1.79 \pm 0.55$ & $1.76 \pm 0.63$ & $\mathrm{NS}$ \\
& $\mathbf{t 6}$ & $1.14 \pm 0.44$ & $1.17 \pm 0.38$ & $\mathrm{NS}$ \\
\hline \multirow{2}{*}{ CAL } & $\mathbf{t 0}$ & $5.58 \pm 1.57^{\mathrm{a}}$ & $5.93 \pm 1.71^{\mathrm{a}}$ & $\mathrm{NS}$ \\
& $\mathbf{t 6}$ & $2.57 \pm 1.20^{\mathrm{b}}$ & $3.09 \pm 1.54^{\mathrm{b}}$ & $\mathrm{NS}$ \\
\hline
\end{tabular}


Table 2: Datas obtained from CAD/CAM system images by Mimics software (t0: Pre-operative, t1: 1 monthaftersurgery, t6: 6 monthsaftersurgery). Statistically significant: $\mathrm{p}<0.05$. NS: Not significant.

\begin{tabular}{lcccc}
\hline & & $\begin{array}{c}\text { Test Group } \\
\text { SCTG+EMD }\end{array}$ & $\begin{array}{c}\text { Control Group } \\
\text { SCTG }\end{array}$ & $\begin{array}{c}\text { Between Test and } \\
\text { Control Groups (p) }\end{array}$ \\
\multirow{2}{*}{ GGV $\left(\mathbf{m m}^{\mathbf{3}}\right)$} & $\mathbf{t 1 - t 0}$ & $14.5 \pm 7.50^{\mathrm{a}}$ & $11.2 \pm 6.36^{\mathrm{a}}$ & $\mathrm{NS}$ \\
& $\mathbf{t 6 - t 0}$ & $11.5 \pm 6.72^{\mathrm{b}}$ & $8.6 \pm 5.00^{\mathrm{b}}$ & $\mathrm{NS}$ \\
GGSA $\left(\mathbf{m m}^{\mathbf{2}}\right)$ & $\mathbf{t 1 - t 0}$ & $49.37 \pm 18.28^{\mathrm{a}}$ & $41.93 \pm 17.43^{\mathrm{a}}$ & $\mathrm{NS}$ \\
& $\mathbf{t 6 - t 0}$ & $42.75 \pm 16.82^{\mathrm{b}}$ & $33.13 \pm 14.36^{\mathrm{b}}$ & $\mathrm{NS}$ \\
\hline
\end{tabular}

Table 3: Spearman Rho correlation analysis (r: correlation coefficient, $\mathrm{p}$ : statistically significance) (*Statistically significant: $\mathrm{p}<0.05$ ).

\begin{tabular}{|c|c|c|c|c|c|}
\hline & & GGSA & GGV & RD & RW \\
\hline \multirow[t]{2}{*}{ PI } & $r$ & -0.664 & -0.703 & 0.618 & 0.331 \\
\hline & $p$ & $0.000 *$ & $0.000^{*}$ & $0.000 *$ & $0.030 *$ \\
\hline \multirow[t]{2}{*}{ GI } & $r$ & -0.623 & -0.345 & 0.561 & 0.494 \\
\hline & $p$ & $0.000 *$ & $0.030 *$ & $0.000 *$ & $0.000 *$ \\
\hline \multirow[t]{2}{*}{ PD } & $r$ & -0.343 & -0.783 & 0.517 & 0.371 \\
\hline & $p$ & $0.030 *$ & $0.000^{*}$ & $0.000 *$ & $0.040^{*}$ \\
\hline \multirow[t]{2}{*}{ CAL } & $r$ & -0.223 & -0.345 & 0.561 & 0.594 \\
\hline & $p$ & $0.020 *$ & $0.030 *$ & $0.000 *$ & $0.000 *$ \\
\hline
\end{tabular}

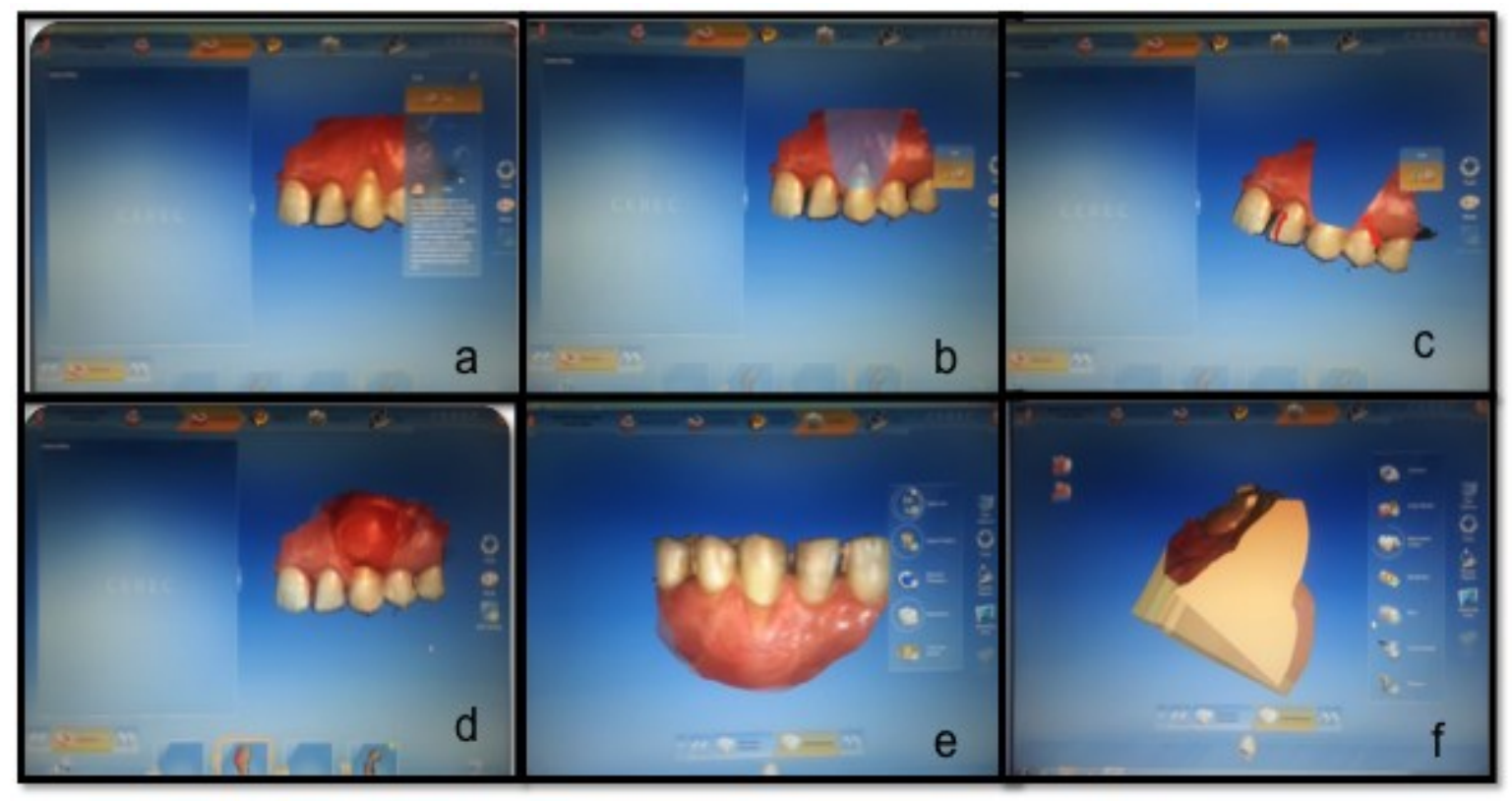

Figure 1: a. Pre-operative 3D image (from CAD-CAM) b. Cutting the operation field from the image field (from CAD-CAM) c. Cut operation field (from CAD-CAM) d. Rescanning operation area at post-operative $1^{\text {st }}$ month (from CAD-CAM) e. Superimposition of images at post-operative $1^{\text {st }}$ month (from CAD-CAM) f. Superimposition of images at post-operative $6^{\text {th }}$ month (from CAD-CAM) 


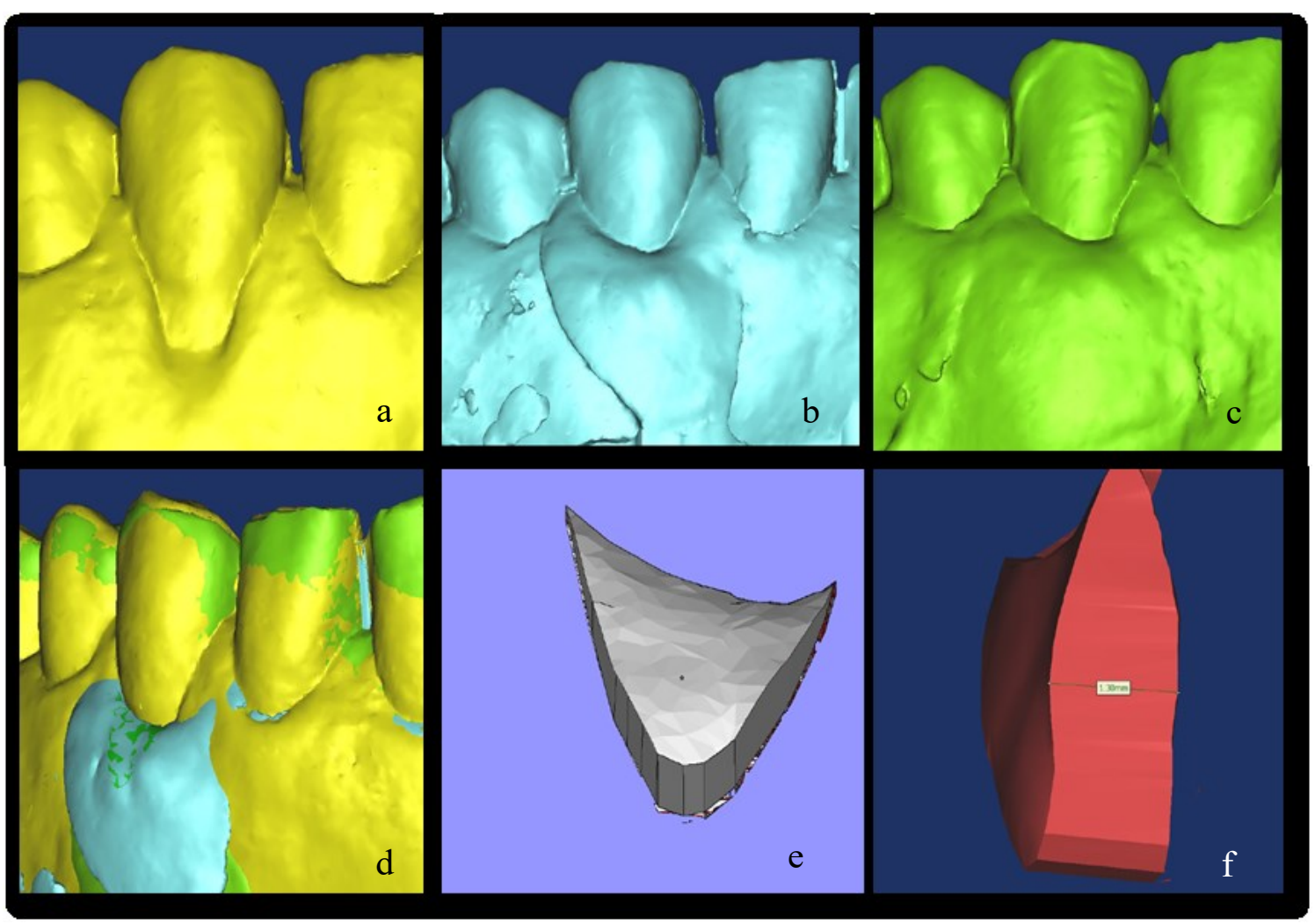

Figure 2: a. Pre-operative 3D image (stl format) b. Post-operative $1^{\text {st }}$ month image (stl format) c. Postoperative $6^{\text {th }}$ month image (stl format) d. Superimposition of images (stl format) e. 3D image of increased gingiva at post-operative $1^{\text {st }}$ month (stl format) f. $3 \mathrm{D}$ image of increased gingiva at post-operative $6^{\text {th }}$ month (stl format)

\section{Discussion}

This is the first study in the literature in which $\mathrm{CAD} / \mathrm{CAM}$ scanners and direct intra-oral digital measurements were used to evaluate the results of GR treatment. In this study, we planned to treat GR by using SCTG and SCTG+EMD in order to overcome aesthetic concerns of patients, to decrease risk for cementum decay and to ease plaque control for patients. The second objective was to use $\mathrm{CAD} / \mathrm{CAM}$ scanners to evaluate GGV and GGSA. In the literature, the terms GGV and GGSA were used for the first time. This research was based not on the initial volume and surface area of the gingiva but on the amount of gingival acquisition.

As the result, the present study, we did not find a significant difference in terms of RH, RW, GGV and GGSA values between two groups. Another treatment method used for treating gingival recession is periodontal plastic surgery procedures applied together with EMD. (13-16) Histological studies show that EMD usage provides a new attachment apparatus, and that it is a regenerative material that provides healing. $(5,17-19)$
While some studies have shown that EMD usage contributes to clinical results in the treatment of gingival recession $(20,21)$, other studies have indicated that a statistically significant difference was not provided with EMD usage. $(15,18,22)$. In our study, it was also found that EMD had no statistically significant contribution to RH, RW, GGV and GGSA.

A number of methods are used to determine the effectiveness of periodontal treatment. Measurement of the thickness of soft tissue can be performed by using dental instruments such as periodontal probe, injection needle and endodontic file (6) reported that the type of periodontal probe and personal factors depending on the person who carries out the measurement have an impact on the measurement of GR with periodontal probing. In an attempt to evaluate clinical data, clinical parameters were measured by periodontal probing in our study. In the literature, there are a limited number of studies which express that 3D digital scanning data can be used to evaluate the results after periodontal treatment. $(8,23-$ 25) 
In a study (2007) done by Windisch et al, CEREC system has used in order to carried out to test the precision and the reliability of $3 \mathrm{D}$ volumetric imaging on alveolar bone defect models. Measurements were carried out on eight pares of samples. It has been reported that the reliability of $3 \mathrm{D}$ optical systems was quite high, based on the statistical data obtained as a result of the study. It has been defined that the digital method that was being investigated was suitable to be used clinically in calculating volumetric changes of oral structures. (26)

Lehmann et al. (2012) (24) have stated that the advantages of using 3D scanners were, that data obtained by $3 \mathrm{D}$ scanners provide visual data for both the dentist and the patient; and enable the determination of the amount of GR and enable its usage in patient training and treatment plan. According to the results obtained from the study conducted by Lehmann et. al, it has been reported that the images obtained from 3D optical scanners and the data obtained by overlapping these images in calculating the volume of GR replicable and reliable.

Although 3D optical scanners provide reliable and accurate results, there is no replicable method today in volumetric evaluation of GR. Volumetric evaluation involves clinical and laboratory procedures, impressions, development of plaster models followed by upload into software program of digitized data which can be derived from the impression. (9)

In a study conducted by Rebele et al. (2014) (13), six patients who received SCTG (tunneling technique) were evaluated. After producing plaster models of six patients, these were scanned and digital images were created; volumetric evaluations were performed on these digital images. The difference as determined by overlapping baseline digital STL images with those at the 1 st month was regarded as $100 \%$. New impressions were taken from patients at 2nd, 3rd, 6th and 12th month and plaster models were prepared accordingly. Average volumetric change was $78 \pm$ $11 \%$ at the 2 nd month and was $75 \pm 15 \%$ at the $3 \mathrm{rd}$ month. No significant difference in the volume of gingival gain was detected in that study at the 6th (63 $\pm 13 \%)$ and 12 th month $(64 \pm 14 \%)$. In the guidance of this information, we evaluated volumetric assessments at the 1st month and 6th month.

When it comes to the discussion of study limitations, $\mathrm{CAD} / \mathrm{CAM}$ devices are expensive and scanning is time-consuming. Admittedly, more significant results could be obtained when the initial gingival marginal thickness was assessed, but in this study, changes in the gingival tissue after surgery were evaluated. Since the separation of attached gingiva and oral mucosa can not be detected well in the images obtained with CAD / CAM scanners, it has not been possible to determine how much of the acquired gingiva is attached gingiva.

\section{Conclusion}

Images from $\mathrm{CAD} / \mathrm{CAM}$ system can be used in calculating the volume and surface area of gained gingiva after the GR treatment. We believe that prospective and longitudinal studies should be conducted in order to evaluate the effectiveness of soft-tissue operations in periodontology by using 3D images. Non-disturbance of digitally stored personal data by personal measurement errors is considered as the most important advantage of these systems. Therefore, volumetric evaluation of different treatment methods used in GR is expected to provide more objective data. Further studies are needed for volumetric analysis of periodontal surgical treatments by using different screening techniques.

Acknowledgments: This study was self-funded by the authors and by the University of YuzuncuYil University (Committee of Research 2014-SBED017).The authors thank the School of Dentistry at YuzuncuYil University for its support.

Conflict of Interest: The authors declare no potential conflicts of interest with respect to the research, authorship, and/or publication of this article.

Author's Contributions: HSA, ASE: Collecting patient data, writing and revision of article,

Ethical issues: All Authors declare that Originality of research/article etc... and ethical approval of research, and responsibilities of research against local ethics commission are under the Authors responsibilities. The study was conducted due to defined rules by the Local Ethics Commission guidelines and audits.

\section{References}

1. Köseoğlu S, Sağlam M, Pekbağrıyanık T, Savran L, Sütçü R. Level of Interleukin-35 in Gingival Crevicular Fluid, Saliva, and Plasma in Periodontal Disease and Health. J Periodontol [Internet]. 2015 Aug [cited 2017 Jan 15];86(8):964-71. Available from: http://www.ncbi.nlm.nih.gov/pubmed/25786564

2. Valderhaug J. Periodontal conditions and carious lesions following the insertion of fixed prostheses: a 10-year follow-up study. Int Dent J [Internet]. 1980 Dec [cited 2017 Aug 16];30(4):296-304. Available from: http://www.ncbi.nlm.nih.gov/pubmed/6935162

3. Goldstein M, Nasatzky E, Goultschin J, Boyan BD, Schwartz Z. Coverage of Previously Carious Roots Is as Predictable a Procedure as Coverage of Intact Roots. J Periodontol [Internet]. 2002 Dec [cited 2017 Aug 16];73(12):1419-26. Available from: http://www.ncbi.nlm.nih.gov/pubmed/12546091

4. Silva RC Da, Joly JC, de Lima AFM, Tatakis DN. Root Coverage Using the Coronally Positioned Flap With or Without a Subepithelial Connective Tissue Graft. J Periodontol [Internet]. 2004 Mar [cited 2017 Aug 16];75(3):413-9. Available from: http://www.ncbi.nlm.nih.gov/pubmed/15088880 
5. Sculean A, Windisch P, Keglevich T, Gera I. Histologic evaluation of human intrabony defects following nonsurgical periodontal therapy with and without application of enamel matrix derivatives. J Periodontol. 2003;74:15360 .

6. Ronay V, Sahrmann P, Bindl A, Attin T, Schmidlin PR Current Status and Perspectives of Mucogingival Soft Tissue Measurement Methods. J Esthet Restor Dent [Internet]. 2011 Jun [cited 2016 Dec 4];23(3):146-56. Available from: http://www.ncbi.nlm.nih.gov/pubmed/21649828

7. Weinländer M, Lekovic V, Spadijer-Gostovic S, Milicic B, Krennmair G, Plenk Jr H. Gingivomorphometry - esthetic evaluation of the crown-mucogingival complex: a new method for collection and measurement of standardized and reproducible data in oral photography. Clin Oral Implants Res [Internet]. 2009 May [cited 2017 Aug 16];20(5):526-30. Available from: http://www.ncbi.nlm.nih.gov/pubmed/19522978

8. Rosin M, Splieth C, Hessler M, Gärtner C, Kordass B, Kocher T. Quantification of gingival edema using a new 3D laser scanning method. J Clin Periodontol [Internet]. 2002 Mar [cited 2016 Dec 4];29(3):240-6. Available from: http://www.ncbi.nlm.nih.gov/pubmed/11940144

9. Strebel J, Ender A, Paqué F, Krähenmann M, Attin T, Schmidlin PR. In Vivo Validation of a Three-Dimensional Optical Method to Document Volumetric Soft Tissue Changes of the Interdental Papilla. J Periodontol [Internet]. 2009 Jan [cited 2016 Dec 4];80(1):56-61. Available from: http://www.ncbi.nlm.nih.gov/pubmed/19228090

10. Seelbach P, Brueckel C, Wöstmann B. Accuracy of digital and conventional impression techniques and workflow. Clin Oral Investig [Internet]. 2013 Sep 21 [cited 2016 Dec 4];17(7):1759-64. Available from: http://www.ncbi.nlm.nih.gov/pubmed/23086333

11. Silness J, Löe H. Periodontal Disease in Pregnancy II. Correlation Between Oral Hygiene and Periodontal Condition. Acta Odontol Scand [Internet]. Taylor \& Francis; 1964 Jan 2 [cited 2016 Dec 4];22(1):121-35. Available from: http://www.tandfonline.com/doi/full/10.3109/00016356408 993968

12. Löe H, Silness J. Periodontal Disease in Pregnancy I. Prevalence and Severity. Acta Odontol Scand [Internet]. Taylor \& Francis; 1963 Jan 2 [cited 2016 Dec 4];21(6):533-51. Available from: http://www.tandfonline.com/doi/full/10.3109/00016356309 011240

13. Rebele SF, Zuhr O, Schneider D, Jung RE, Hürzeler MB. Tunnel technique with connective tissue graft versus coronally advanced flap with enamel matrix derivative for root coverage: a RCT using 3D digital measuring methods. Part II. Volumetric studies on healing dynamics and gingival dimensions. J Clin Periodontol. 2014 Apr;41:593603.

14. McGuire M, Scheyer E, Nunn M. Evaluation of human recession defects treated with coronally advanced flaps and either enamel matrix derivative or connective tissue: comparison of clinical parameters at 10 years. J Periodontol. 2012 Nov;83(11):1353-62.
15. Roman A, Soancă A, Kasaj A, Stratul S-I. Subepithelial connective tissue graft with or without enamel matrix derivative for the treatment of Miller class I and II gingival recessions: a controlled randomized clinical trial. J Periodontal Res [Internet]. 2013 Oct [cited 2016 Dec 4];48(5):563-72. Available from: http://www.ncbi.nlm.nih.gov/pubmed/23317049

16. Zuhr O, Rebele S, Schneider D, Jung R, Hürzeler M. Tunnel technique with connective tissue graft versus coronally advanced flap with enamel matrix derivative for root coverage: a RCT using 3D digital measuring methods. Part I. Clinical and patient-centred outcomes. J Clin Periodontol. 2014 Oct;41:582-92.

17. Rasperini G, Silvestri M, Schenk R, Nevins M. Clinical and histologic evaluation of human gingival recession treated with a subepithelial connective tissue graft and enamel matrix derivative (Emdogain): a case report. Int J Periodontics Restor Dent. 2000;20(3):269-75.

18. Henriques $\mathrm{P}$, Pelegrine A, Nogueira A, Borghi M. Application of subepithelial connective tissue graft with or without enamel matrix derivative for root coverage: a splitmouth randomized study. J Oral Sci. 2010;52(3):463-71.

19. Hammarström L, Heijl L, Gestrelius S. Periodontal regeneration in a buccal dehiscence model in monkeys after application of enamel matrix proteins. J Clin Periodontol [Internet]. 1997 Sep [cited 2016 Dec 4];24(9 Pt 2):669-77. Available from: http://www.ncbi.nlm.nih.gov/pubmed/9310871

20. Moses O, Artzi Z, Sculean A, Tal H, Kozlovsky A, Romanos GE, et al. Comparative Study of Two Root Coverage Procedures: A 24-Month Follow-Up Multicenter Study. J Periodontol [Internet]. 2006 Feb [cited 2016 Dec 4];77(2):195-202. Available from: http://www.ncbi.nlm.nih.gov/pubmed/16460244

21. Pilloni A, Paolantonio M, Camargo PM. Root Coverage With a Coronally Positioned Flap Used in Combination With Enamel Matrix Derivative: 18-Month Clinical Evaluation. J Periodontol [Internet]. 2006 Dec [cited 2016 Dec 4];77(12):2031-9. Available from: http:/www.ncbi.nlm.nih.gov/pubmed/17209788

22. Aroca S, Keglevich T, Nikolidakis D, Gera I, Nagy K, Azzi R, et al. Treatment of class III multiple gingival recessions: a randomized-clinical trial. J Clin Periodontol [Internet]. 2010 Jan [cited 2016 Dec 4];37(1):88-97. Available

http://www.ncbi.nlm.nih.gov/pubmed/19968743

23. Mehl A, Gloger W, Kunzelmann K-H, Hickel R. A New Optical 3-D Device for the Detection of Wear. J Dent Res [Internet]. 1997 Nov 8 [cited 2017 Aug 16];76(11):1799807. Available from: http://www.ncbi.nlm.nih.gov/pubmed/9372798

24. Lehmann KM, Kasaj A, Ross A, Kämmerer PW, Wagner W, Scheller H. A New Method for Volumetric Evaluation of Gingival Recessions: A Feasibility Study. J Periodontol [Internet]. 2012 Jan [cited 2016 Dec 4];83(1):50-4. Available http://www.ncbi.nlm.nih.gov/pubmed/21563950 
25. Lehmann KM, Kasaj A, Ross A, Willershausen I, Schmidtmann I, Staedt $\mathrm{H}$, et al. A novel method for evaluating periodontal recession: a feasibility study. Int J Comput Dent [Internet]. 2011 [cited 2017 Aug 16];14(4):297-307. Available from: http://www.ncbi.nlm.nih.gov/pubmed/22324221
26. Windisch SI, Jung RE, Sailer I, Studer SP, Ender A, Hämmerle CHF. A new optical method to evaluate threedimensional volume changes of alveolar contours: a methodological in vitro study. Clin Oral Implants Res [Internet]. 2007 Oct [cited 2016 Dec 4];18(5):545-51. Available from:

Copyright (C) 2016 The Author(s); This is an open-access article distributed under the terms of the Creative Commons Attribution License (http://creativecommons.org/licenses/by/4.0), which permits unrestricted use, distribution, and reproduction in any medium, provided the original work is properly cited. All Rights reserved by international journal of Medical Science and Discovery. 